\title{
LA SALUD Y LA REGULACIÓN ALIMENTARIA EUROPEA: EL NIVEL DE RIESGO TOLERADO
}

\section{HEALTH AND EUROPEAN FOOD REGULATIONS: THE TOLERATED RISK LEVEL}

Marc Suñer ${ }^{1}$

DOI: https://doi.org/10.37767/2591-3476(2020)25

\section{Comentario a}

T. Boer \& Zonen BV y Staatssecretaris van Economische Zaken

Tribunal de Justicia de la Unión Europea

\author{
Disponible en \\ https://bit.ly/2YdgiKH
}

\begin{abstract}
RESUMEN:
T. Boer \& Zonen es una empresa neerlandesa productora de carne. Por violaciones de la normativa alimentaria europea, se le imponen sendas multas que, tras ser recurridas, culminan en una cuestión prejudicial del tribunal en cuestión ante Tribunal de Justicia de la Unión Europea sobre si la refrigeración de los productos puede entenderse realizada dentro de los camiones frigoríficos (encontrándose estos en las dependencias del matadero), como pretende la empresa, o debemos atender a la literalidad de la norma y otros requisitos, que este proceso solo puede entenderse realizado en el sitio especificado como "matadero". Por la propia naturaleza del bien jurídico y el elevado nivel de precaución y riesgo tolerable que ha asumido la Unión Europea, el Tribunal de Justicia de la Unión Europea falla en favor de la interpretación consonante con dichos principios y de manera desfavorable para la empresa.
\end{abstract}

\section{ABSTRACT}

T. Boer \& Zonen is a meat producing Dutch company. Due to breaches of the European food legislation, it is fined and, after the appeal process, culminates in a preliminary ruling from the appeals court to the Court of Justice of the European Union about whether it can be interpreted that the refrigeration process requirement was met if it was performed in the freezing trucks (being these located within the slaughterhouse), as the company pretends, or it must be understood as met only if it was performed as the literality of the rule expresses and also other requirements. Given the nature of the legally protected good and the elevated level of precaution and risk tolerance assumed by the European Union, the Court of Justice of the European Union rules in favor of the interpretation compatible with said standards and against the company. 
PALABRAS CLAVE: Prevención, Salud, Riesgo, Protección, Cooperación.

KEY WORDS: Prevention, Health, Risk, Protection, Cooperation

\section{Origen del litigio y desarrollo}

El litigio se origina porque las instalaciones de T. Boer \& Zonen, empresa neerlandesa productora de carne de ternera son inspeccionadas por la autoridad neerlandesa de seguridad alimentaria y de los productos de consumo (Nederlandse Voedsel -en Warenautoriteit). En estas, se comprueba su infracción al Reglamento (CE) No 853/2004 del Parlamento Europeo y del Consejo de 29 de abril de 2004, el cual ordena que la carne deberá refrigerarse para garantizar una temperatura no superior a $3^{\circ} \mathrm{C}$, en el caso de los despojos, y de $7^{\circ} \mathrm{C}$, en los otros tipos de carne. Las autoridades sanitarias neerlandesas verificaron que esto no solo se incumplió de forma puntual sino que era una práctica estandarizada. Por esto, la empresa recibió sendas multas por importe de 20.000 euros, las cuales, tras la interposición de un recurso administrativo, fueron reducidas.

Posteriormente, T. Boer \& Zonen recurrió por vía judicial dicha resolución administrativa, siendo esta desestimada por el tribunal de primera instancia. Ante esto, recurrió en apelación. Su argumentación puede resumirse en que la refrigeración ordenada por la normativa europea puede alcanzarse después del traslado al vehículo frigorífico. La Administración, por su parte, afirma que la refrigeración debe realizarse en el matadero y que el vehículo frigorífico no puede asimilarse a un matadero, por lo que la temperatura indicada deberá ser alcanzada antes del traslado a dicho vehículo.

Sobre esta discrepancia, surgida a raíz de una posible interpretación de la normativa europea, el Tribunal de Apelación en materia económica plantea al Tribunal de Justicia de la Unión Europea una cuestión prejudicial, instrumento que tienen todos los jueces de la Unión Europea, para que dicho tribunal se pronuncie acerca de cuál es la interpretación correcta de una disposición de legislación comunitaria, y así garantizar una aplicación uniforme de esta. En concreto, le pregunta que si, según lo dispuesto, “¿la refrigeración de la carne puede efectuarse en el propio matadero, de suerte que la carga de la carne en un vehículo frigorífico solo podrá empezar una vez que la carne haya alcanzado una temperatura no superior a $7^{\circ} \mathrm{C}$, o también puede efectuarse la refrigeración (...) en el vehículo frigorífico, en tanto que este no abandone los locales del matadero?"

Una vez presentado con la cuestión prejudicial, y con las observaciones escritas que pueden realizar tanto las partes del litigio como los Estados Miembros (Países Bajos, Francia, Hungría y Rumanía), la Comisión y la institución que haya adoptado el acto en cuestión, el Tribunal de Justicia se dispone a contestarla.

\section{La argumentación del Tribunal}

Primero, reconoce que, según las definiciones normativas, difícilmente podría considerarse como realizada en el matadero una refrigeración en camiones frigoríficos, por el simple hecho de encontrarse estos dentro de las dependencias del matadero. Para esto, menciona que según los puntos 1 y 3 del capítulo VII de la sección primera del Reglamento $853 / 2004$, la inspección post mortem deberá ir inmediatamente seguida de una refrigeración en el matadero para garantizar una temperatura de toda la carne no superior 
a $7^{\circ} \mathrm{C}$, enfatizando el hecho de que el propio reglamento utiliza la palabra "matadero". Seguidamente, el Tribunal se remite al punto 1.16 del anexo I de dicho reglamento, que define al matadero como "el establecimiento donde se sacrifican y faenan animales cuya carne está destinada al consumo humano"; y también se remite al literal C del apartado 1 del artículo 2 del Reglamento 852/2004, que define "establecimiento" como "cualquier unidad de empresa del sector alimentario".

Segundo, determina la falta de idoneidad de estos vehículos para realizar las labores de enfriamiento. Para esto, se apoya en los informes de la Comisión Europea y del Estado francés que respectivamente señalan que "un vehículo frigorífico (...) está destinado al transporte de carne y no interviene en el proceso de sacrificio, faenado y refrigeración de la carne antes de su almacenamiento o transporte. La función de dichos vehículos consiste principalmente en transportar la carne y no en refrigerarla, pues su equipo de refrigeración está diseñado para mantener baja la temperatura durante el transporte" y que "la refrigeración en la cámara frigorífica de los mataderos permite aplicar frío inmediatamente en circunstancias óptimas, a fin de evitar el desarrollo de bacterias y, por consiguiente, garantizar un nivel elevado de seguridad alimentaria, en contraste con la que puede lograrse en un vehículo frigorífico, donde la temperatura solo puede controlarse de manera empírica".

Posteriormente, argumenta que el literal b del apartado 1 del artículo 4 del Reglamento 853/2004 ordena que "operadores de empresa alimentaria pondrán en el mercado productos de origen animal fabricados en la Comunidad únicamente si han sido elaborados y manipulados exclusivamente en establecimientos que (...) hayan sido registrados por la autoridad competente o, cuando sea preceptivo en virtud del apartado 2, hayan recibido autorización". Dicho apartado 2 condiciona el ejercicio de estas actividades a que ora se haya hecho una inspección in situ por parte de las autoridades competentes, ora se haya recibido una autorización condicional para dicho fin, cosa que no ha sucedido en este caso.

Por último, recalca el Tribunal el objetivo principal que persigue la normativa en materia de higiene, esto es, según el considerando 9 del Reglamento 853/2004, "garantizar un elevado nivel de protección de los consumidores", es irreconciliable con la laxa interpretación de la misma que pretende T. Boer \& Zonen.

\section{Contenido de los reglamentos}

\section{Reglamento $853 / 2004$}

En sus considerandos, reconoce que determinados productos alimenticios pueden presentar ciertos peligros para la salud humana y que por ende son necesarias ciertas normas higiénicas específicas, que recaen sobre fabricantes y autoridades competentes. Reconoce que uno de los objetivos es que, a nivel comunitario, se alcance un elevado nivel de protección para los consumidores. En cuanto a definiciones, hace una remisión a los reglamentos cuyo contenido posteriormente detallaremos; y define "matadero" como "el establecimiento donde se sacrifican y faenan animales cuya carne está destinada al consumo humano".

Ordena que todos los operadores de la empresa alimentaria que pongan en el mercado productos de origen animal fabricados en la Comunidad, hayan cumplido con los requisitos que establece el Reglamento 852/2004; y que no podrán ejercer sus actividades 
a menos de que la autoridad competente los haya autorizado para tal, para lo cual se requiere una inspección in situ.

En sus anexos, detalla el procedimiento que deberá seguirse para el procesamiento y venta de carne de vacuno. Este explica que una vez sacrificados los vacunos, tienen lugar labores de separación y clasificación de las partes del animal destinadas para el consumo humano de las que no, o que hayan contravenido alguna regla sanitaria, para posteriormente realizar una inspección post mortem, que tiene por objeto verificar condiciones de salubridad establecidas en el propio reglamento. No debemos confundir esta parte del proceso con el despiece y el deshuesado, fase posterior pero distinta del sacrificio, que consiste en la clasificación de la carne, ya toda destinada al consumo humano, en sus distintas presentaciones comerciales. Para esto, el capítulo V dispone que "la carne se mantendrá a una temperatura no superior a $3^{\circ} \mathrm{C}$ para los despojos y $7^{\circ} \mathrm{C}$ para el resto de la carne mediante una temperatura ambiente no superior a $12^{\circ} \mathrm{Co}$ un sistema alternativo de efectos equivalentes".

Para la fase siguiente, el almacenamiento, y sobre la cual incide el litigio, se dispone que "La carne deberá alcanzar la temperatura establecida en el punto 1 (esto es, no superior a $3^{\circ} \mathrm{C}$ para los despojos y $7^{\circ} \mathrm{C}$ para el resto de la carne) antes de ser transportada y permanecer a dicha temperatura durante el almacenamiento". Sobre esto, destaca que dicha temperatura deberá alcanzarse antes del transporte.

\section{Reglamento $852 / 2004$}

Este reglamento contiene las definiciones a las que se remitía el reglamento 853/2004, sobre "establecimiento", que es definido como "cualquier unidad de una empresa del sector alimentario".

\section{Reglamento $178 / 2002$}

Define el Principio de cautela en su artículo 7, sobre que "tras haber evaluado la información disponible (...) se observe la posibilidad de que hayan efectos nocivos para la salud (...) podrán adoptarse medidas provisionales de gestión del riesgo para asegurar el nivel elevado de protección por el que ha optado la Comunidad". El artículo 8 reconoce como objetivo de la legislación alimentaria la protección de los intereses de los consumidores y el artículo 17 establece en las empresas la responsabilidad de controlar la adecuación a los estándares que la normativa señala y menciona que los Estados podrán aplicar sanciones a los infractores.

\section{Derecho a la salud}

\section{Posición del derecho a la salud en el ordenamiento europeo}

La OMS se refiere a la salud como "un estado de completo bienestar físico, mental y social, y no solamente la ausencia de afecciones o enfermedades". Así entendida, la salud es reconocida como un derecho por el numeral 1 del artículo 25 de la Declaración Universal de Derechos Humanos en cuanto que "toda persona tiene derecho a un nivel de vida adecuado que le asegure, así como a su familia, la salud y el bienestar", así como por el artículo 35 de la Carta de Derechos Fundamentales de la Unión Europea "Toda persona tiene derecho a acceder a la prevención sanitaria y a beneficiarse de la atención sanitaria $(. . .)^{\prime \prime}$ que tendrá, dicha carta, "el mismo valor jurídico que los tratados", según el artículo 6.1 del Tratado de la Unión Europea. De igual forma, la Carta Social Europea de 1961, en 
su artículo 11, señala que "las Partes Contratantes se comprometen a (...) eliminar las causas de una salud deficiente". Sin embargo, podemos notar una cierta amplitud en esto, como bien señala Xavier Seuba Hernández que "una definición tan amplia plantea problemas a la hora de acotar el régimen normativo referido a la salud" (Seuba Hernández, 2010: 39). Es, por ello, necesario hacer precisiones; y sobre ellas continúa al decir que "(el derecho a la salud encuentra) su razón de ser en la protección de un bien jurídico que con frecuencia requiere acciones positivas", el cual "(tiene) el propósito último de proteger, promocionar y mejorar la salud". (Seuba Hernández 2010: 40). Es decir que por su carácter positivo, su realización es más compleja y multifacética que si se tratase de un derecho-abstención (aunque en algunos casos pueda serlo).

El artículo 168 del Tratado de Funcionamiento de la Unión Europea establece que "al definirse y ejecutarse todas las políticas y acciones de la Unión se garantizará un alto nivel de protección de la salud humana (...) la acción de la Unión, que complementará las políticas nacionales, se encaminará a mejorar la salud pública, prevenir las enfermedades humanas y evitar las fuentes de peligro para la salud". En el marco de las competencias compartidas, la Unión actuará normalmente y, como es el caso, para hacer una armonización de las legislaciones. La particularidad es que una vez que la Unión Europea ejerce su capacidad normativa, desplazará la competencia estatal, en virtud del art. 2.2 del Tratado de Funcionamiento de la Unión Europea.

A esta acción coordinada por la Unión Europea es a la que, con ciertas matizaciones se refiere Seuba Hernández cuando dice que "la globalización de la salud pública recurre al Derecho Internacional como herramienta para una gestión de la salud pública mundial que disminuya la vulnerabilidad frente a las enfermedades (...) se sitúa en una esfera caracterizada por la necesidad de cooperación" (Seuba Hernández, 2010: 41). La precisión es que el derecho de la Unión Europea no es Derecho Internacional pero sí tiene el componente de cooperación interestatal al que se hace referencia.

\section{Distintas vertientes del derecho a la salud}

Teniendo en mente que muchas veces se requieren actuaciones positivas, podemos precisar, entre varios, dos enfoques de actuación: la medicina y la prevención. La primera tiene un enfoque individual y se caracteriza grosso modo por la existencia de un paciente, quien presenta una enfermedad, y requiere ser tratado por un especialista (Zalazar y Carranza, 2019: 17); sin perjuicio de que la existencia de este especialista deba ser garantizado por un sistema de salud público, que sin duda haría este enfoque un tanto más colectivo (Zalazar y Carranza, 2019: 20).

El enfoque preventivo lo catalogamos de colectivo en cuanto que no existe un individuo preciso sobre el cual deba recaer la asistencia sanitaria sino que, a través de políticas públicas, el Estado debe crear las condiciones necesarias para garantizar dicho "estado de bienestar físico" en un momento previo a la existencia de la enfermedad. Para que esto sea posible, debemos "asignar a la salud la doble consideración (...) de derecho fundamental del individuo e interés de la comunidad" (León Alonso, M, 2010: 76).

Precisamente a esta vertiente derecho a la salud es a la que hacen referencia los considerandos 2, 4 y 9 del reglamento 853/2004 cuando dicen que "determinados productos alimenticios pueden presentar peligros para la salud humana, y ello hace necesario el establecer normas higiénicas específicas (...) en particular con los alimentos de origen 
animal, con respecto a los cuales se han observado con frecuencia riesgos microbiológicos y químicos", que "Por lo que respecta a la salud pública, dichas normas (las que establecen normas sanitarias específicas para la producción y puesta en mercado de los productos enumerados en el Anexo I del Tratado) contienen una serie de principios comunes, referentes sobre todo a las responsabilidades de fabricantes y autoridades competentes, a los requisitos estructurales, operativos e higiénicos para los establecimientos, a los procedimientos de autorización de éstos y a los requisitos para el almacenamiento y el transporte y el marcado sanitario" y que “Los objetivos principales (...) son: garantizar un elevado nivel de protección de los consumidores, asegurando la inocuidad alimentaria (...)".

Lo característico de esta vertiente del derecho a la salud es que es directamente aplicable, a diferencia de las demás. El llamado derecho de atención sanitaria es catalogado de principio rector, más que de norma jurídica: "por el simple hecho de que el precepto se incluya en un texto constitucional (o legal), no queda, sin más, convertido en una norma jurídica. Es necesario, además, que tenga "estructura lógica" de norma jurídica: que sea una orden, mandato, prohibición -con la correspondiente consecuencia de su incumplimiento- o, en definitiva, que delimite esferas de correlativos derechos y deberes entre sujetos" (Garrido Falla, F, 1985: 579). Sin embargo, opiniones disonantes afirman que "la incompletud de la norma es un acto deliberado del constituyente que, debido al carácter contingente de las circunstancias, ha preferido no vincularse definitivamente, permitiendo así que una norma de rango inferior adapte el ordenamiento jurídico a las necesidades de cada momento. En este sentido la Constitución es una norma de definición de valores principales y, en consecuencia, una norma de reenvíos." (Nieto, A, 1983: 394)

\section{Principio de precaución y el estándar elegido}

Una vez trazada la línea divisoria entre ambas aristas del derecho a la salud, no resulta complejo entender tanto las razones que motivan la normativa europea como la del faIlo. La prevención y un alto nivel de protección han sido los estándares que ha escogido el legislador europeo cuando trata sobre protección preventiva sobre la salud en materia alimenticia. Pero estos lineamientos no tienen su origen en el Derecho Comunitario, sino que se remontan a la Carta Mundial de la Naturaleza aprobada por la Asamblea General de las Naciones Unidas en 1982. Más específicamente, la consagración internacional del principio de precaución se produjo en 1992, en cuyo principio 15 se indica: “Con el fin de proteger el medio ambiente, los Estados deben aplicar ampliamente las medidas de precaución conforme a sus capacidades".

El estándar de protección elegido podemos apreciarlo en el artículo 168 del Tratado de Funcionamiento de la Unión Europea que dice: "al definirse y ejecutarse todas las políticas y acciones de la Unión se garantizará un alto nivel de protección de la salud humana"; mientras que el artículo 191 del Tratado de Funcionamiento de la Unión Europea que concreta el principio de precaución: "la política de la Unión (...) tendrá como objeto alcanzar un nivel de protección elevado (...) se basará en los principios de cautela y acción preventiva (...)". De dicho principio de precaución, la Comisión se ha pronunciado en el sentido de que "la Comunidad ha perseguido constantemente el objetivo de un elevado nivel de protección, en materia de (...) salud humana. Concretamente, el artículo 7 del Reglamento 178/2002, que se aplica en el caso en cuestión, desarrolla el principio y lo denomina principio de cautela: “(...) cuando (...) se observe la posibilidad de que haya efectos nocivos para la salud pero siga existiendo incertidumbre científica, podrán adoptarse 
medidas provisionales de gestión de riesgo para asegurar el nivel elevado de protección de la salud por el que ha optado la comunidad".

\section{Implicaciones en la normativa y el fallo}

Entonces, es comprensible que no se permita que el refrigeramiento ocurra en los camiones refrigeradores, ya que estos tanto son inidóneos para alcanzar los objetivos de refrigeración necesarios para alcanzar un estándar de salud preventiva deseable como que no han sido inspeccionados y corroborado su adecuación a los estándares técnicos, de diseño y equipamientos que figuran en el anexo III del reglamento 853/2004. La pretensión interpretativa de T. Boer \& Zonen es disonante con los estándares deseados por el Derecho de la Unión Europea. Es por eso que no se trata de una simple rigurosidad innecesaria sobre definiciones sino sobre una aplicación exigente de una legislación por cuyas venas corre el germen de la aplicación rigurosa, en atención al bien jurídico que se protege de manera preventiva.

\section{REFERENCIAS BIBLIOGRÁFICAS}

- Garrido Falla, F. (1985). Comentarios a la Constitución. Madrid: Civitas.

- León Alonso, M. (2010). La protección constitucional de la salud. Madrid: La Ley.

- Nieto, A. (1983). Peculiaridades jurídicas de la norma constitucional. Madrid: Revista de Administración Pública.

- Seuba Hernández, X. (2010). La protección de la salud ante la regulación internacional de los productos farmacéuticos. Madrid: Marcial Pons.

- Zalazar, C. y Carranza, G. (2019). Aproximación sistémica al concepto de Derecho a la Salud. En Zalazar, C. y Carranza, G. (dir.): Derecho y salud en perspectiva: estudios de Derecho a la salud. Córdoba: Advocatus. 